Veterinary Serum and Vaccine Research Institute, Abbasia, Cairo

\title{
IMMUNOLOGICAL STUDIES ON SIMULTANEOUS VACCINATION WITH PNEUMO-3 AND PPR INACTIVATED VACCINE IN SHEEP
}

(With 3 Tables)

By

W.M. GHATTAS; G. HUSSEIN; FATMA SAYED; LAILA ABDEL AZEEM; SAMIRA S. TAHA and SAMIA A. AYAD

(Received at 19/12/2006)

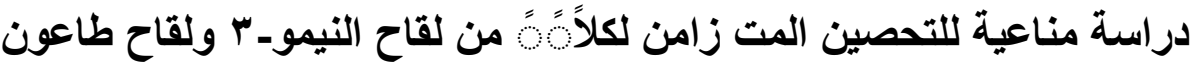
المجترات الصغيرة المثبط في الأغنام

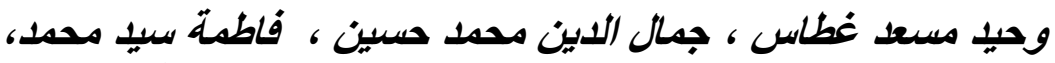

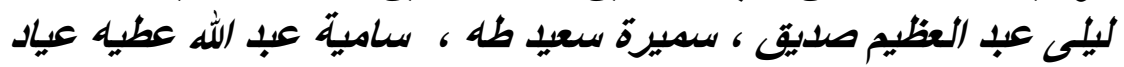

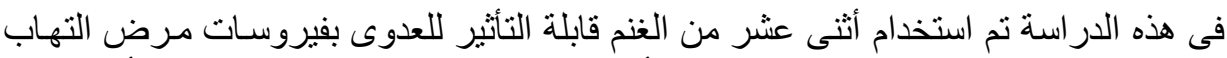

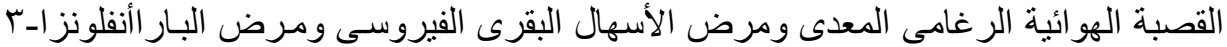

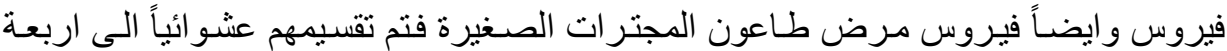

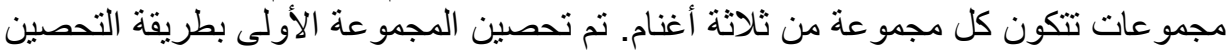

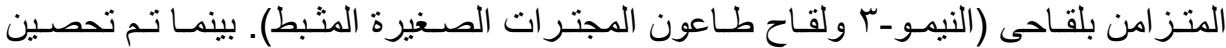

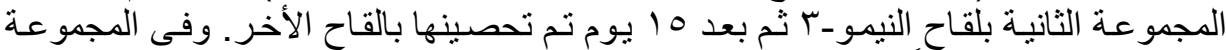

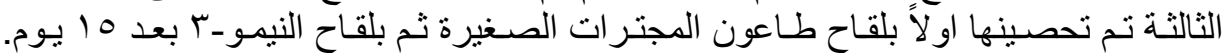

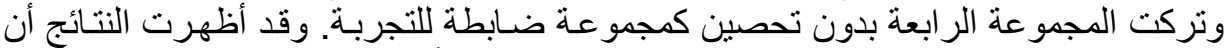

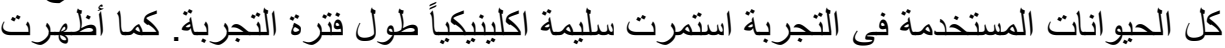

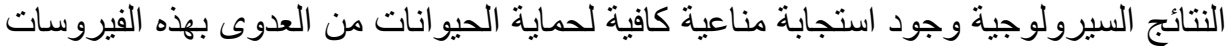

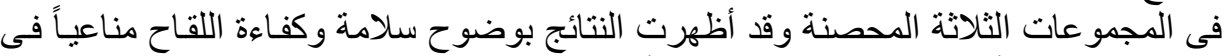

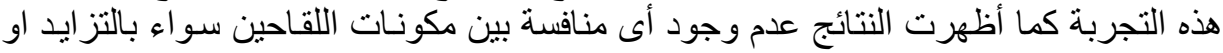

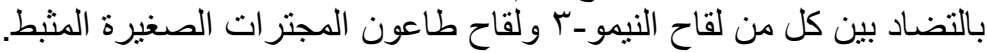

\section{SUMMARY}

A total of twelve seronegative sheep, against infectious bovine rhinotracheitis (IBR), bovine viral diarrhoea (BVD) and parainfluenza-3 (PI-3) and peste des petits ruminants (PPR) viruses were randomly divided into four groups (each group consists of 3 sheep). The first group, received simultaneous vaccination with pneumo-3 and inactivated PPR vaccines, while the second group received pneumo-3 vaccine and after 2 weeks that received inactivated PPR vaccine. The third group received firstly the inactivated PPR vaccine, then received inactivated pneumo-3 vaccine after 2 weeks, while, the fourth group was kept as 
non-vaccinated control group. All tested animals remained clinically normal throughout the whole experimental period. Very satisfactory serological responses were detected in animals, simultaneously vaccinated with both vaccines. No differences were detected in serum neutralizing antibody titres against IBR, BVD, PI-3 and PPR viruses, in sheep which received inactivated PPR vaccine, neither before nor after vaccination with pneumo-3 vaccine. The results clearly indicated the safety and efficacy of simultaneous vaccination of sheep with pneumo-3 and inactivated PPR vaccine without any competition for the response to individual vaccine. Also there is neither synergistic nor antagonistic effect for the two vaccines in sheep.

Key words: Pneumo-3vaccine, inactivated PPR vaccine, sheep

\section{INTRODUCTION}

Respiratory virus affections as bovine viral diarrhoea (BVD), infectious bovine rhinotracheitis (IBR) and parainfluenza-3 (PI-3) represent the most important and drastic upset among fattening sheep and are widely spread throughout the world. These affections constitute major causes of morbidity and mortality rates in feed lot sheep despite the high prevalence and economic importance of respiratory virus affection (St. George, 1971, Liess et al., 1983).

On the other hand, peste des petits ruminants (PPR) is an acute highly contagious viral disease of goats and sheep, caused by Morbillivirus (paramyxoviridae family) and is closely related to but quite distinct from rinderpest virus (Gibbs et al., 1979), PPR has been reported to occur in Egypt in limited outbreaks (El-Sanousi et al., 1989; Ismail et al., 1990 and El-Alloway et al., 1993 and Mouaz et al., 1995). Hence, the prepared inactivated PPR vaccine to be used in this investigation was undertaken by Mirchamsy et al. (1974), who succeeded in preparation of killed vaccine of cell-cultured rinderpest virus, also, Scot and Witcomb (1958) who compared vaccines produced by inactivation of a suspension of rinderpest infected bovine spleen using of $1 \%$ formalin and Provost et al. (1969) who tested cell cultured rinderpest virus inactivated with $B$. propiolactone in oil adjuvant. Although, vaccination against PPR is not practiced in Egypt.

At the same time, probable future outbreaks of PPR virus might cause great losses in sheep and goat population, also, vaccination is considered a basic tool for control of infectious viral diseases (Hansen et al., 1995) other than eradication nor medication.

The increasing number of vaccines which administered to the animals at any age and at any time without accurate programs of 
vaccination makes it necessary to search the effect of the inactivated PPR vaccine on safety and efficacy of combined inactivated respiratory virus vaccine (pneumo-3 vaccine) which containing BVD, IBR and PI-3 viruses and the potential for simultaneous vaccination is being greater because of higher quality of vaccines produced.

Efforts, funds and time would be saved at launching vaccination campaign for more than one disease, provided the protective response to each vaccine is not impaired.

The aim of this work is to study the effect of inactivated PPR vaccine on BVD, IBR and PI-3 antibody titres by vaccination of sheep with the prepared inactivated PPR vaccine, before, simultaneously and/or after vaccination with combined inactivated respiratory viruses vaccine (pneumo-3).

\section{MATERIALS and METHODS}

\section{Viral strains:}

\subsection{BVD virus:}

Egyptian bovine viral diarrhoea virus (Iman strain) with a titre of $7 \log _{10} \mathrm{TCID}_{50} / \mathrm{ml}$, firstly, isolated and identified by Baz (1975).

\subsection{IBR virus:}

A reference Egyptian strain of infectious bovine rhinotracheitis virus (Abou Hammad strain) with a titre of $8 \log _{10} \mathrm{TCID}_{50} / \mathrm{ml}$, was firstly isolated by Hafez et al. (1976).

\subsection{PI-3 virus:}

A reference Egyptian strain of parainfluenza-3 virus (strain 45) with a titre of $8 \log _{10} \mathrm{TCID}_{50} / \mathrm{ml}$ which was isolated and identified by Singh and Baz (1966).

All virus entities were propagated and titrated on Madin Darby bovine kidney (MDBK) cell culture, which has been proved free of any adventitious agents. These viruses were supplied by Rinderpest-Like Disease Research Dept., Veterinary Serum and Vaccine Research Institute, Abbasia, Cairo.

\subsection{PPR Virus:}

A local cell culture, live attenuated PPR virus (Samia et al., 2000) was supplied by the Department of Rinderpest Research, Veterinary Serum and Vaccine Research Institute, Abbasia, Cairo. It was used for preparation of inactivated PPR vaccine which used for experimental animal vaccination and SNT.

All live virus strains were used to estimate the induced antibodies in vaccinated sheep using SNT. 
2. Animals: A total of twelve (12) IBR, BVD, PI-3 and PPRVsusceptible, clinically healthy sheep of local breed of about 4-6 months old, were used in this study. These sheep were housed in the same experimental facilities at Veterinary Serum and Vaccine Research Institute, Abbasia, Cairo.

Blood samples were collected for serum preparation and tested to be free from antibodies against BVD, IBR, PI-3 and PPR viruses prior to vaccination.

3. Inactivants: 2-bromomethyl ammonium bromide $\left(\mathrm{C}_{2} \mathrm{~N}_{7} \mathrm{Br}_{2} \mathrm{~N}\right.$, Panneac, Qumica, SA Barcelona, Spain) was used for preparation binary ethyleneimine (BEI).

4. Sodium thiosulphate: It was obtained from Difco Laboratories and it was prepared as $20 \%$ solution. It was used to stop the action of BEI.

5. Alhydrogel solution: Aluminium hydroxide $2 \%$ gel (Honil, limited, London, UK). It was used as stabilizing adjuvant in vaccine preparation. It was sterilized by autoclaving for 30 minutes at $121^{\circ} \mathrm{C}$, then aliquoted in bottles and stored at $4^{\circ} \mathrm{C}$.

6. Thiomersal (Merthiolate): It was used as a vaccine preservative. It was added to the vaccine at final concentration of $0.001 \%$.

\section{Vaccines:}

\subsection{Combined inactivated vaccine (Pneumo-3):}

- The vaccine formulation comprised three viruses, BVD, IBR and PI-3, was already produced and registered with a patent name (Pneumo-3 vaccine).

- This vaccine was prepared and used for sheep vaccination in the dose and route according to the method of El-Sabbagh et al. (1995) and Samira et al. (2001).

- Pneumo-3 vaccine used in this experiment was gently supplied from Rinderpest Like Disease Dept., Veterinary Serum and Vaccine Research Institute, Abbasia, Cairo. It was taken from batch 002/2006.

\subsection{Inactivated PPR vaccine:}

The preparation of inactivated PPR vaccine was under taken according to Fayed et al. (2000) and Hussein (2001).

8. Experimental Design: All sheep (twelve sheep) were randomly divided into 4 groups each of 3 sheep, as follows:

Group I: This group was simultaneously vaccinated with the combined inactivated pneumo-3 and inactivated PPR vaccines. The combined inactivated pneumo-3 vaccine was inoculated in each animal at the dose of $3 \mathrm{ml}$, by deep I/M according to Hansen et al. (1995). While the 
inactivated PPR vaccine was inoculated at the dose of $2 \mathrm{ml} \mathrm{S} / \mathrm{C}$ route for each animal after the procedure applied by Fayed et al. (2000) and Hussein (2001) then followed by booster dose after 2 weeks by the same vaccinal dose and the same route for each animal of this group.

Group II: This group was vaccinated with inactivated PPR vaccine before vaccination with combined inactivated pneumo-3 vaccine by 2 weeks. Two prepared vaccines (inactivated PPR and combined inactivated pneumo-3 vaccines) were used at the same vaccinal dose, same routes (S/C for PPR vaccine and deep I/M for pneumo-3 vaccine) and the same interval for booster dose as in animal grouping I).

Group III: This group was vaccinated with the prepared inactivated PPR vaccine after the vaccination with combined inactivated pneumo-3 vaccine by 2 weeks with same vaccinal doses, inoculation routes, and same interval time for boostering as in group (I).

Group IV: This group was kept without vaccination as non-vaccinated contact control group.

9. Serological Investigation: All the collected serum samples were assayed for presence of specific antibodies against all vaccinal viruses (BVD, IBR, PI-3 and PPR vaccine) using serum neutralization test (SNT) in microtitre plates, following the procedure described by Dannacher and Martel (1978) and Rossi and Kiessel (1971). The serum neutralizing antibody titres ( $\mathrm{SN}-\mathrm{Ab})$ titres were expressed as $\log _{10}$ TCID $_{50}$ of serum dilution that protected $50 \%$ of the wells of microtitre plate following the calculation procedure of Reed and Muench (1938).

\section{RESULTS}

The results of the tests were illustrated in Tables 1, 2, and 3.

Table 1: Mean serum neutralizing antibody titres of vaccinated sheep with inactivated PPR vaccine before vaccination with combined inactivated pneumo-3 vaccine

\begin{tabular}{|c|c|c|c|c|}
\hline \multirow{2}{*}{} & \multirow{2}{*}{ Inactivated PPR } & \multicolumn{3}{|c|}{ Combined Inactivated Pneumo-3 vaccine } \\
\cline { 3 - 5 } & & BVD & IBR & PI-3 \\
\hline $1 \mathrm{WPV}$ & $0.00^{*}$ & & & \\
\hline $2 \mathrm{WPV}$ & $1.15^{* *}$ & & & $0.30^{*}$ \\
\hline $4 \mathrm{WPV}$ & 1.30 & $0.00^{*}$ & $0.90^{* *}$ & $0.30^{*}$ \\
\hline $6 \mathrm{WPV}$ & 1.60 & $0.90^{* *}$ & 1.40 & $1.00^{* *}$ \\
\hline $8 \mathrm{WPV}$ & 1.82 & 1.35 & 1.70 & 1.50 \\
\hline $10 \mathrm{WPV}$ & 1.60 & 1.70 & 1.65 & 1.77 \\
\hline $12 \mathrm{WPV}$ & 1.25 & 1.60 & 1.50 & 1.60 \\
\hline $16 \mathrm{WPV}$ & 1.20 & 1.45 & 1.30 & 1.40 \\
\hline $20 \mathrm{WPV}$ & 1.90 & 1.25 & 1.20 & 1.30 \\
\hline $24 \mathrm{WPV}$ & 0.9 & 1.20 & & \\
\hline
\end{tabular}


Table 2: Mean serum neutralizing antibody titres expressed in $\log _{10}$ of simultaneous vaccination of combined inactivated pneumo-3 and inactivated PPR vaccine

\begin{tabular}{|c|c|c|c|c|}
\hline \multirow{2}{*}{} & \multirow{2}{*}{ Inactivated PPR } & \multicolumn{3}{|c|}{ Combined Inactivated Pneumo-3 vaccine } \\
\cline { 3 - 5 } & & BVD & IBR & PI-3 \\
\hline $0 \mathrm{WPV}$ & $0.00 *$ & $0.00 *$ & $0.20^{*}$ & $0.3 *$ \\
\hline $2 \mathrm{WPV}$ & $1.00 * *$ & $0.90 * *$ & $0.90 * *$ & $1.10 * *$ \\
\hline $4 \mathrm{WPV}$ & 1.20 & 1.45 & 1.55 & 1.65 \\
\hline $6 \mathrm{WPV}$ & 1.75 & 1.80 & 1.90 & 2.10 \\
\hline $8 \mathrm{WPV}$ & 1.90 & 1.85 & 2.00 & 2.10 \\
\hline $10 \mathrm{WPV}$ & 1.85 & 1.75 & 1.75 & 1.90 \\
\hline $12 \mathrm{WPV}$ & 1.68 & 1.65 & 1.70 & 1.80 \\
\hline $16 \mathrm{WPV}$ & 1.30 & 1.33 & 1.35 & 1.35 \\
\hline $20 \mathrm{WPV}$ & 1.20 & 1.20 & 1.25 & 1.30 \\
\hline $24 \mathrm{WPV}$ & 1.00 & 0.90 & 1.00 & 1.10 \\
\hline
\end{tabular}

Table 3: Mean serum neutralizing antibody titres expressed in $\log _{10}$ of vaccinated sheep with inactivated PPR vaccine after vaccination with combined inactivated pneumo-3 vaccine

\begin{tabular}{|c|c|c|c|c|}
\hline \multirow{2}{*}{} & \multirow{2}{*}{ Inactivated PPR } & \multicolumn{3}{|c|}{ Combined Inactivated Pneumo-3 vaccine } \\
\cline { 2 - 5 } & & BVD & IBR & PI-3 \\
\hline $0 \mathrm{WPV}$ & & $0.00 *$ & $0.30 *$ & $0.30 *$ \\
\hline $2 \mathrm{WPV}$ & $0.00 *$ & $0.90 * *$ & $1.10 * *$ & $1.20 * *$ \\
\hline $4 \mathrm{WPV}$ & $1.00 * *$ & 1.55 & 1.65 & 1.65 \\
\hline $6 \mathrm{WPV}$ & 1.20 & 1.77 & 1.85 & 1.90 \\
\hline $8 \mathrm{WPV}$ & 1.75 & 1.77 & 1.75 & 1.90 \\
\hline $10 \mathrm{WPV}$ & 1.95 & 1.75 & 1.70 & 1.75 \\
\hline $12 \mathrm{WPV}$ & 1.85 & 1.60 & 1.35 & 1.35 \\
\hline $16 \mathrm{WPV}$ & 1.65 & 1.30 & 0.90 & 0.90 \\
\hline $20 \mathrm{WPV}$ & 1.35 & 1.15 & 0.90 & \\
\hline $24 \mathrm{WPV}$ & & $* 1^{\text {st }}$ vaccination & For each vaccination & \\
\hline
\end{tabular}

\section{DISCUSSION}

The use of simultaneous vaccination has found much attention recently and could greatly simplify prophylactic effect induced by vaccination and so control of such diseases with reducing time, effort and cost of the campaign which make it economically more acceptable (Joseph and Hedger, 1984 and Gugium et al., 1989).

The monitoring of humoral immune response post vaccination is a mean for evaluation of the protective capacity of vaccines, and the commonly used serological test is the neutralization test which is considered as a queen test for determination of serum neutralizing antibody titres (SN Ab). SNT has been extensively used as a measure of immune response against combined inactivated respiratory virus vaccine (Pneumo-3) and inactivated PPR vaccine (Rossi and Kiesel, 1971). 
The results obtained in Tables $(1,2$ and 3$)$ revealed that the mean $\mathrm{SN}-\mathrm{Ab}$ titres of vaccinated sheep at 4 weeks post first vaccination, were fully sufficient to protect susceptible animals from infection with respiratory viruses (IBR, BVD and PI-3) as reported by Zuffa and Feketova (1980), Mihylovic et al. (1979) and Bittle et al. (1968) who reported that the minimum acceptable titre of protective level against IBR, PI-3 and BVD viruses are 0.6, 0.6 and 0.90 respectively and there is no significant differences could be detected in the mean SN antibody titres against IBR, PI-3 and BVD viruses in the three groups post vaccination of sheep during the whole experimental periods, and these results were coincide with Matsuoka et al. (1966), who used PI-3 virus with Pasteurella multocida and Pasteurella haemolytica. Tribe et al. (1969) who applied vaccination of Guinea pigs and colostrum deprived calves with bovine Adeno-3 virus with parainfluenza virus vaccine.

Matsuoka et al. (1972) also applied vaccination of calves with inactivated PI-3 and IBR simultaneously with killed Pasteurella multocida and Pasteurella haemolytica vaccine. Sampson et al. (1972) applied trials of immunization to calves with an inactivated IBR and PI3 vaccine. Simultaneously with Pasteurella bacterin and Ghally et al. (1996) who studied the effect of sheep pox vaccine and combined inactivated respiratory virus vaccine (with patent name "Triangle-4") in the immune response of calves against IBR, PI-3 and BVD viruses and El-Sabbagh et al. (1999), who applied immunological studies on simultaneous vaccination of combined inactivated respiratory virus vaccine with Rift valley fever vaccine in sheep and he concluded that there is no significant effect on the safety and efficacy of simultaneous inoculation of sheep with pneumo-3 with Rift valley fever vaccine.

Concerning the synchronous vaccination of sheep with PPR vaccine, with other vaccines were reported before as Afaf et al. (2003) for attenuated PPR, attenuated RVF and BCG, Nahed et al. (2003) for attenuated PPR and polyvalent clostridial vaccine, Nahed et al. (2002) for PPR vaccine and combined Pasteurella multocida vaccine and Samir et al. (1999) for PPR and sheep pox combined vaccine.

The increasing number of vaccines makes it necessary to design special schemes for their national use to save time, efforts and fund, other successful trials of simultaneous vaccination of animals with more than one vaccine were reported before (Macadam, 1964), for rinderpest and black quarter or anthrax spore vaccine, (Brown and Taylor, 1966) for rinderpest and contagious bovine pleuropneumonia, (Darie et al., 1979) for foot and mouth disease and clostridia and anthrax (Polydora et 
al., 1980) for foot and mouth disease (FMD) and anthrax, enterotoxaemia and enzootic abortion, (Joseph and Hedger, 1984) for FMD and haemorrhagic septicaemia (Hedger et al., 1986) for rinderpest and FMD (Osman et al., 1987) for rinderpest and BCG, Osman et al. (1991) for rinderpest and haemorrhagic septicaemia, Osman et al. (1997) who applied synchronous vaccination of cattle with rinderpest and BCG vaccine Ghally et al. (1996) sheep pox and combined inactivated respiratory virus vaccine and finally El-Sabbagh et al. (1999), who applied simultaneous vaccination between combined inactivated respiratory virus vaccine (Pneumo-3) and Rift valley fever vaccine.

In this study, very satisfactory immune response was obtained, for both vaccines used, to pneumo-3 vaccine and inactivated PPR vaccine, such results in tables 1, 2 and 3, assure that the simultaneous vaccination had no effect on the immune response of sheep against both pneumo-3 vaccine and inactivated PPR vaccine. So on conclusion, our results could be indicated clearly the safety and efficacy of simultaneous vaccination of pneumo-3 vaccine with inactivated PPR vaccine without any completion neither synergistic nor antagonistic effect, and it could be recommended to use for sheep vaccination.

\section{REFERENCES}

Afaf A. Abdel Wahab; Eman, M. Sayed; Hanan S. Abdel Raouf and Salib, O.R. (2003): Response of sheep to simultaneous inoculation with attenuated PPR vaccine, RVFV and BCG. Egypt. Vet. Med. Assoc., 63 (2): 239-247.

Baz, Thanaa, I. (1975): Isolation, characterization and serological studies on bovine viral diarrhoea and mucosal disease in Egypt. Thesis Ph.D., Fac. Vet. Med., Cairo Univ.

Bittle, J.L. (1968): Vaccination for bovine viral diarrhoea-mucosal disease. J. Amer. Vet. Med. Assoc., 192 (6): 861-865.

Brown, R.D. and Taylor, W.P. (1966): Simultaneous vaccination of cattle against rinderpest and contagious bovine pleuropneumonia. Bull. Epizoot. Dis. Afr., 14: 161.

Dannacher, G. and Martel, J.L. (1978): Titration of antibody to bovine viral diarrhoea virus by micro-method of serum neutralization. Recueil de Medicine Veterinire, 154 (1): 31-37.

Darie, P.; Lanita, C.; Perasanu, D.; Eustavivici, O.; Simon, M. and Miracescu, C. (1979): Simultaneous vaccination of intensively reared lambs against anaerobes, anthrax and foot and mouth 
disease. Lucar, 1 Instito Luido Cercetari Veterinare biopreparts Si Pasteur, 15: 75.

El-Allawy, T.A.; Laila, S.A. and Abdel Rahim, I.H. (1993): Serological studies on peste des petits ruminants (PPR) in Upper Egypt. Proc. $2^{\text {nd }}$ Sci. Cong. Egypt. Soc., Cattle Disease, 57 Dec. 1993, Assiut, Egypt, 2: 278-289.

El-Sabbagh, M.M.; Samira, S.T.; Ghally, H.M. and Saad, M.S. (1995): Binary ethyleneimine as an inactivant for infectious bovine rhinotracheitis (IBR), bovine viral diarrhoea (BVD) and parainfluenza-3 (PI-3) viruses and its application for vaccine production. Beni-Suef Vet. Med. Res., 5 (2): 29-57.

El-Sabbagh, M.M.; M. Abd El-Samae; Samira S. Taha; Ghally, H.M. and Saad, S.M. (1999): Simultaneous vaccination of combined inactivated respiratory virus vaccine (Pneumo-3) with Rift valley fever vaccine in sheep. Vet. Med. J., Fac. Vet. Med., Cairo Univ., Vol. 47, July 1999, Res. No. 3.

El-Sanousi, A.A.; Abo El-Hassan, D.E.; Arab, R.M.; Shalaby, M.A.; Saber, M.S. and Reda, I.M. (1989): An outbreak of rinderpest like disease among Egyptian wild rams. Vet. Med. J., 137 (2): 261-280.

El-Sabbagh, M.M.; El-Sawalhy, A.A.; Samira, S.T. and Ghally, H.M. (2001): Evaluation of combined inactivated respiratory virus vaccine (Pneumo-4) in pregnant cow dams. J. Vet. Med. Res., Vol. III, Research No. 2.

Fayed, A.A.; Khodeir, M.H.; Mouaz, M.A. and Nahed A. Kamal (2000): Preparation of specific inactivated peste des petits ruminants vaccine. Vet. Med. J., 48 (4): 625-632.

Ghally, H.M.M.; Abdel Samae, M.M.; El-Sabbagh, M.M. and Samira Said Taha (1996): The effect of sheep pox and combined inactivated respiratory virus vaccine on immune response of calves. Beni-Suef Vet. Res. J., Vol. VI (1), Res. No. (6), 47-55.

Gibbs, E.P.J.; Taylor, W.P.; Lawman, M.J.P. and Bryant, J. (1979):

Classification of peste des petits ruminants virus as the fourth member of the genus Morbillivirus. Inter. Virol. J., 11 (5): 268274.

Gugiun, I.; Stribn, C.; Constsntinescu, C.; Vior, E.; Costa, V.; Danes, M.; Graria, M. and Gugin, M. (1989): Results of administration of vaccines against FMD and Pasteurellosis in cattle. Lucararile Institute de Cercetari Veterinar Biopreparat, Pasteur, 18: 47. 
Hafez, S.M.; Thanaa I. Baz.; Mohsen, A.Y.A. and Mounira H. Zehran (1976): Infectious bovine rhinotracheitis in Egypt and serological identification of the virus. J. Egypt. Vet. Med. Assoc., 36 (1): 129-139.

Hansen, D.E.; Mecoy, R.D. and Armstrong, D.A. (1995): Six vaccination trials in feed lot lambs for control of lamb respiratory disease complex. Agri. Practice, 16 (9): 19-25.

Hedger, R.S.; Taylor, W.P.; Barenette, R.R.; Pier, R. and Harpham, D. (1986): Simultaneous vaccination of cattle against foot and mouth disease and rinderpest. Trop. Anim. Hlth. Prod., 18.

Hussein, G.M. (2001): Studies on the use of different adjuvant and inactivators to produce an inactivated PPRV vaccine. Ph.D. Thesis, Fac. Vet. Med., Alex. Univ.

Ismail, I.M. and House, J. (1990): Evidence of identification of peste des petits ruminants from goats in Egypt. Arch. Exper. Vet. Med., 44 (3): 471-474.

Jensen, R.; Grinner, L.A.; Chow, T.L. and Brown, W.W. (1978): IBR in feed lot cattle. I. Pathology and symptoms. Proc. M.S. Livestock Saniti Assoc., 59: 189-199.

Joseph, P.E. and Hedger, R.S. (1984): Serological response of cattle to simultaneous vaccination against FMD and haemorrhagic septicaemia. Vet. Rec., 20:414-424.

Liess, B.; Orban, S. and Frey, H.R. (1983): Diagnosis of border disease of sheep, exemplified by an outbreak of abortion, wasting and lamb mortality. Tierarztliche, Umschau, 38 (8): 574.

Macadam, I. (1964): The response of Zebu cattle to tissue culture rinderpest vaccine mixed in (1) black quarter vaccine and (2) anthrax spore vaccine. Bull. Epiz. Dis., afr., 12: 401.

Matsouka, T.; Fokerts, T.M. and Gale, G. (1972): Evaluation in calves of an inactivated IBR and PI-3 vaccine combined with Pasteurella bacterin. J. Am. Vet. Med. Assoc., 160 (3): 333337.

Matsuoka, J.K.; Gale, G.; Ose, E. and Berkmann, R. (1966): Immunity to experimental parainfluenza and Pasteurella challenge following calfhood vaccination. Live Stocksan Assoc., 104108.

Mehanna, A.M.; Hanan S. Abdel Raouf and Daoud, A.M. (2004): The performance of both peste des petits ruminants (PPR) and Brucella melitensis, Rev-1 vaccines, concurrently administered to sheep. Mansoura Vet. Med. J., 6 (1): 131-142. 
Mihaylovic, B.; Cvetovic, A.; Kazmanovic, M.; Vuhobrat, D.; Asuin, R. and Lazurevic, T. (1979): Comparison of vaccine against respiratory viral diseases of cattle, infectious bovine rhinotracheitis (IBR) and parainfluenza-3 (PI-3) viruses. Veterinarski, Glasrik, 33 (1) 33-39.

Mirchamsy, H.; Shafyi, A.; Bahrami, S.; Nazari, P. and Akbarzadeh, J. (1974): Active immunization of cattle with killed vaccine prepared from cell cultured rinderpest virus. Res. Vet. Sci., 17 (2): 242-247.

Mouaz, M.A.; Soliman, A.K.K.; Khodeir, M.H.; Samia, A.A. and Nadia, M.H. (1995): Differentiation between rinderpest and peste des petits ruminants virus by the indirect immunofluorescent techniques. Egypt. Vet. Med. J., 55 (5): 1047-1055.

Nahed, I.H.M.; Khamis; Amina A. El-Bayomy; Afaf A. Abdel El-Wahab and Hanan, M.S. El-Zawahry (2002): Immune response of sheep vaccinated with combined Pasteurella multocida and peste des petits ruminants vaccine. Egypt. Vet. Med. Assoc., 2: 205-217,

Osman, O.A.; Mahmoud, A.A.; Mousa, M.A. and Athanious, S. (1987): A preliminary study on vaccination of calves with rinderpest and BCG vaccine. Assiut Univ., Vet. Med. J., 19 (37): 39.

Osman, O.A.; Mouaz, M.A.; El-Zeidy, S.A.S.; Dimitri, R.A.; Gergis, S.M. and Yousef, R.R. (1991): Serological response of cattle to synchronous vaccination of rinderpest and BCG vaccine. Egypt. J. Agri. Res., 69 (4).

Osman, O.A.; Seham Abdel Rasheed, A.; Makeen, S.; Dimitri, R.A.; Mouaz, M.A. and Yousef, R.R. (1990): The simultaneous inoculation of cattle with rinderpest and haemorrhagic septicaemia vaccines. Assiut Vet. Med. J., 23 (45): 57.

Polydorau, K.; Papasolomontos, P.; Hadjisavaas, T.H.; Economides, T.H.; Efithiow, G.; Pitizolis, G.; Hadjizenonos, L.; Sellers, R.F.; Gibbs, E.P.J.; Herihman, K.A.J.; Parker, L.; Rowe, L.W.; Mowat, G.N. and Ownes, H. (1980): Investigation of foot and mouth disease in Cyprus 1972-1975. Bull. Off. Intern. Epiz., 927 (9/10): 863.

Provost, A.; Borredon, L. and Maurice, Y. (1969): Revite, Elev. Med. Vet., Pays Trop., 22, 473.

Mehanna, A.M.; Hanan S. Abdel Raouf and Daoud, A.M. (2004): The performance of both peste des petits ruminants (PPR) and 
Brucella melitensis, Rev-1 vaccines, concurrently administered to sheep. Mansoura Vet. Med. J., 6 (1): 131-142.

Reed, L.J. and Muench, H. (1938): A simple method for estimating fifty percent end point. Amer. J. Hyg., 27: 493-497.

Rossi, C.R. and Kiesel, G.K. (1971): Microtitre tests for detecting antibody in bovine serum to parainfluenza-3 virus (PI-3), infectious bovine rhinotracheitis virus (IBR) and bovine viral diarrhoea virus (BVD). Microbiolo., 22: 32-36.

Samia, A.A. Ayad; Mouaz, M.A.; Nahed, A. Kamel; Afaf, A. and Daoud, A.M. (2000): Thermostabilizing potential of L-glutamic acid monosodium salt and other factors improving the quality of peste de petits ruminants virus vaccine. Egypt. J. Immun., 7 (2): 21-27.

Samir, S.S.; Wafaa, A. Zaghloul; Soad M. Soliman; Nahed A. Kamel and Mouaz, M.A. (1999): Trials of vaccination of small ruminants using a combined PPR and sheep pox vaccine. Alex. J. Vet. Sci., 15 (4): 721-731.

Samira S. Taha; El-Sabbagh, M.M.A. and Ghally, H.M. (2001): Preparation of combined inactivated BVD, IBR, PI-3 and respiratory syncytia virus (BRSV). Egypt. Vet. Med. Assoc., 61 (4): 251-263.

Sampson, G.R; Matsuoka, T.; Olson, R.O.; Marott, J.A. and Tonkinson, L.V. (1972): Clinical approach of an inactivated bovine rhinotracheitis, parainfluenza-3 vaccine with Pasteurella bacterium. Vet. Med. Small Animal Clin., 67 (12): 1345-1358.

Scott, G.R. and Witcomb, M.A. (1958): E. Afr. Vet. Res., Org. Annual Report, 1956-57, p. 15.

Singh, K.V. and Baz Thanaa I. (1966): Isolation of parainfluenza-3 virus from water buffaloes in Egypt. Nature land, 210: 616-652.

St. George (1971): Actively and passively acquired antibody to mucosal disease and parainfluenza-3 viruses in sheep. Aust. Vet. J., 47 (9): 428-533.

Tribe, G.W.; Karenek, A.D.; Kerry, J.B. and While, G. (1969): A combined bovine parainfluenza-3 and bovine adenovirus vaccine. Vet. Res., 85: 299-303.

Zuffa, A. and Fekeotova, N. (1980): Protective action of inactivated adjuvanted IBR vaccine against experimental infection. Veterinaria Med., 25 (1): 51-61. 